Indexed by

Scopus METHODS FOR CALCULATING RECTANGULAR
SECTION BEAMS MADE OF WOOD AND CONCRETE

DOA

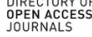

Crossref

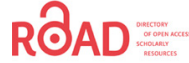

Bulgakov Alexey Grigorievich Southwest State University, Kursk, Russia
Dubrakova Ksenia Olegovna Southwest State University,

Kursk, Russia
Aseev Viacheslav Yurievich Southwest State University, Kursk, Russia

KOBSON

Key words: wood-concrete connection, wood-concrete structures, concrete-wood structured mine doi:10.5937/jaes0-34494

Cite article:

Grigorievich Alexey B., Olegovna Ksenia D., Yurievich Viacheslav A. (2021) METHODS FOR CALCULATING RECTANGULAR SECTION BEAMS MADE OF WOOD AND CONCRETE, Journal of Applied Engineering Science, 19(4), 1035 - 1039, DOI:10.5937/ jaes0-34494

Online aceess of full paper is available at: www.engineeringscience.rs/browse-issues 


\title{
METHODS FOR CALCULATING RECTANGULAR SECTION BEAMS MADE OF WOOD AND CONCRETE
}

\author{
Bulgakov Alexey Grigorievich ${ }^{1}$, Dubrakova Ksenia Olegovna², Aseev Viacheslav Yurievich ${ }^{3 *}$ \\ 'Southwest State University, Kursk, Russia
}

The research aimed to study methods for calculating wood-concrete beams of rectangular cross-section when testing building structures according to the ultimate limit state. The article focuses on the comparison of theoretical methods for calculating structures and considers several methods of fastening the samples of a typical wood-concrete beam. There were obtained experimental data of the ultimate limit state for each sample and carried out a comparative analysis of the most advantageous scheme of fastening the sample parts. The scientific novelty is in the development of an algorithm for calculating composite wood-concrete beams of rectangular cross-sections. As a result, numerical comparison of the values for calculating a typical wood-concrete beam using two of the methods under consideration was given, experimental studies were carried out, as well as a comparative analysis of the obtained theoretical and experimental results.

Key words: wood-concrete connection, wood-concrete structures, concrete-wood structured mine

\section{INTRODUCTION}

Nowadays, in many European countries, for the reconstruction or construction of new buildings, there is a growing tendency to share materials such as concrete and wood $[1,2]$. This is explained primarily by the fact that wood is environmentally friendly, concrete has high availability, as well as the presence of many other properties of these materials that effectively replace each other.When considering the project of composite wood-concrete structures, the joint work of wood and concrete requires additional study due to the relevance of the wooden structures behavior study, and the possible introduction of concrete mixtures in them to increase the strength characteristics, as well as the mutually beneficial behavior of materials [3,4]. Structural solutions such as "wood-concrete" seem to be beneficial for both the timber and concrete market: the former will benefit from the trend towards standardization and market expansion $[5,6]$, while the latter will meet environmental requirements and better differentiate in a competitive landscape $[7,8]$. At the same time, an important advantage of the wood-concrete element work is improving the strength and acoustic characteristics of short-span elements in buildings, which is of practical interest in the design, in particular, of domestic buildings $[9,10]$. When calculating deformable statically definable wood-concrete structures of a combined section, it can be used the integral estimates method, with the help of which the required linearization of the problem is carried out, the temporary fixation of non-equilibrium deformation signs. The assumption is that a rigid connection can be used for an idealized cross-section model is also used in $[11,12]$. Fastening methods, that provide a rigid connection, are considered in $[13,14]$, while the loading method is selected, including, relying on the behavior studying of bending wood with a concrete element [15, 16], and without [17].

\section{THEORY AND EXPERIMENTAL METHODS}

When calculating the combined wood-concrete beam, a deformation model of the section was adopted. We presume that concrete and timber work together along the entire length of the beam, concrete in compression, timber in tension. In this case, the stress diagram is two-valued: rectangular in the compressed and stretched zones (see Fig. 1).

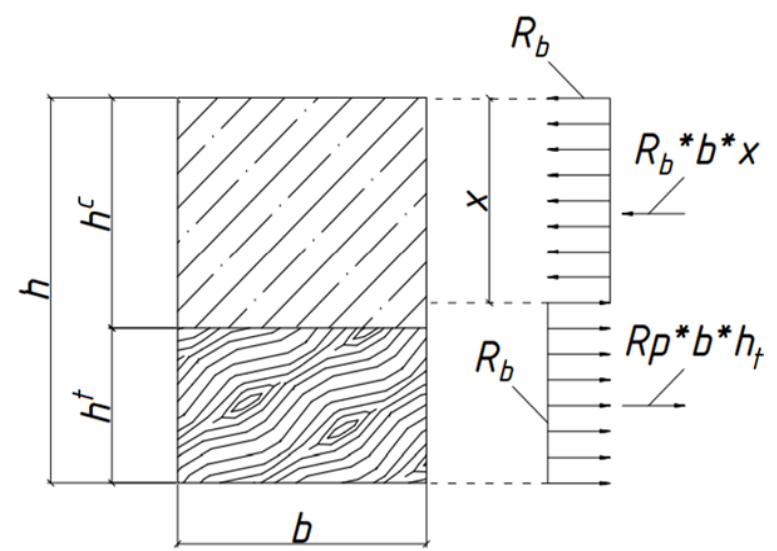

Figure 1: Diagram of cross-sectional forces in bending

Let us consider the efforts in a bent wood-concrete beam with a rectangular section of width $b$, the height of a wooden element ht, and the height of reinforced concrete hc. In this case, the total height of the beam is $h=h t+h c$. Let us denote the height of the compressed zone as $x$, and assume that the neutral axis passes through the reinforced concrete element. The first condition for the balance of external and internal forces for the element under consideration: the sum of all forces is zero: 
$R_{b} * b * x=R_{p} * b * h_{t}$

Using (1), we express the height of the compressed zone:

$$
x=\frac{R_{p} * h_{t}}{R_{b}}
$$

Equation (2) shows that the compressed zone height is directly proportional to the wood tensile strength and the height of the wood element, according to (2) and Fig.1.

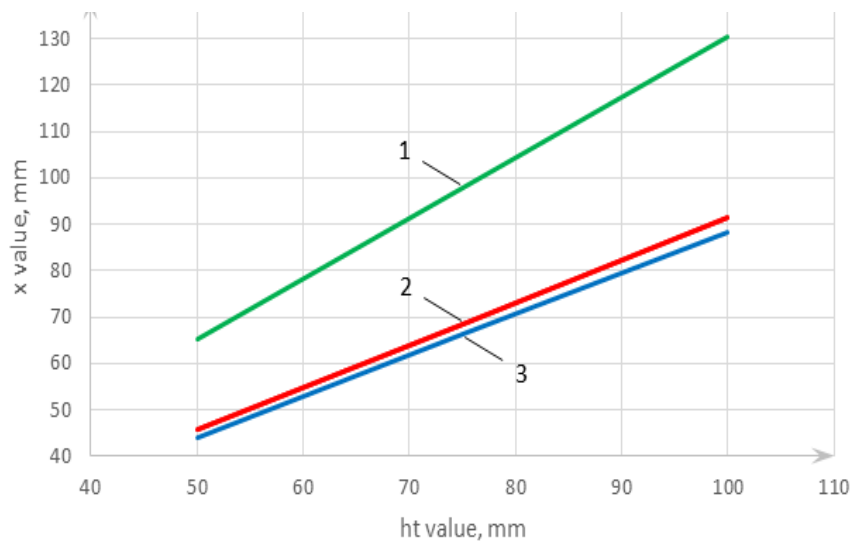

Figure 2: Dependence of the compressed zone height on the height of the wooden element: 1 - B20-grade concrete, first-grade pine wood; 2 - B20-grade concrete, second-grade pine wood; 3 - concrete B30-grade,

\section{first-grade pine wood.}

Let us write down the condition for the strength of the normal section of the considered combined wood-concrete bending beam:

$$
\begin{aligned}
& R_{b} * b * x *\left(h-\frac{h_{t}}{2}-\frac{x}{2}\right)=M^{c} \\
& b * h_{t} * R_{p} *\left(h-\frac{h_{t}}{2}-\frac{x}{2}\right)=M^{t}
\end{aligned}
$$

To calculate the considered bending combined beam, you can apply the method using the modification factor $\mathrm{n}[1]$ :

$n=E_{c} / E_{t}$

where: Ec is the elasticity modulus of concrete in bending, Et - is the elasticity modulus of wood in tension. Applying the modification factor $n$, one can express the values of the idealized cross-section in the following formulas [1]:

$A_{i}=n A_{c}+A_{t}$

where: $\mathrm{Ai}$ is the area of an idealized section,Ac is the cross-sectional area of the concrete part, At is cross-sectional area of a wooden part,li is the inertia moment of the idealized section, Ic is the inertia moment of the concrete part,It is the inertia moment of the wooden part. The inertia moment of the cross-section of a timber-concrete beam is defined as:

$I_{i}=I_{t}+A_{t} a_{t}^{2}+n\left(I_{c}+A_{c} a_{c}^{2}\right)$.

The distance between the gravity center of the wood piece and the idealized cross-section can be calculated as: $a_{t}=\frac{n A_{c} e}{n A_{c}+A_{c}}, a_{c}=e-a_{t}$

where: $\mathrm{e}$ is the distance between the gravity center of the wood and concrete part, a_c - is the distance between the gravity center of the concrete part and the idealized cross-section.The normal stresses distribution in the cross-section of a wood-concrete composite structure is determined by the formulas:

$$
\begin{aligned}
& \sigma_{c, 1}=n \frac{M}{I_{i}}\left(-0,5 h_{c}-a_{c}\right), \sigma_{c, 2}=n \frac{M}{I_{i}}\left(0,5 h_{c}-a_{c}\right) \\
& \sigma_{t, 1}=n \frac{M}{I_{i}}\left(-0,5 h_{t}+a_{t}\right), \sigma_{t, 2}=n \frac{M}{I_{i}}\left(0,5 h_{t}+a_{t}\right)
\end{aligned}
$$

The tensile strengths at the upper (Mu,c1) and lower (Mu,c2) edges of the concrete part can be obtained from the following strength conditions:

$$
\begin{gathered}
\sigma_{c, 1}=n \frac{M_{u, c 1}}{I_{i}}\left(-0,5 h_{c}-a_{c}\right)=R_{b}, \\
\sigma_{c, 2}=n \frac{M_{u, c 2}}{I_{i}}\left(0,5 h_{c}-a_{c}\right)=R_{b t}
\end{gathered}
$$

where: $\mathrm{Rb}$ is the concrete compressive strength, Rbt is the concrete tensile strength. The ultimate strength $(\mathrm{Mu}, \mathrm{t})$ in a wooden part should be determined from the strength condition (12):

$$
\frac{a_{t} M_{u, t}}{I_{i} f_{t, 0, d}}+\frac{0,5 h_{t} M_{u, t}}{I_{i} f_{m d}}=1.0
$$

where: ft,0,d - wood tensile strength, fmd - wood bending strength. From the condition for the limit moment of resistance, it can be expressed the equation:

$F=\frac{M u * 3}{l^{2}}$

Let us observe a 1-meter long wood-concrete beam loaded with concentrated forces in $1 / 3$ of the span, with a section of $100 \times 75 \mathrm{~mm}$ made of elements: concrete

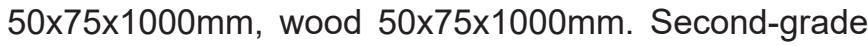
pine is taken as the material of the wooden element, and the concrete element was made from B15-grade concrete. According to the first calculation method results, the force and the maximum moment were determined, equal to $\mathrm{F}=2.45 \mathrm{kN}, \mathrm{M}=0.816 \mathrm{kN}{ }^{*} \mathrm{~m}$. According to the method considered in research [1], the calculated force was $F=2.98 \mathrm{kN}$, and the moment was $\mathrm{M}=0.99$ $\mathrm{kN} * \mathrm{~m}$. Using considered calculation algorithms, it was possible to obtain the values of the critical stresses of a wood-concrete beam. The results of the calculating methods under consideration are comparable in this design solution context. The choice of the most accurate calculation method will be based on further experimental studies.

\section{EXPERIMENTAL SECTION}

In the laboratory of Southwestern State University, tests of wood-concrete beams of combined cross-section under the action of short duration loads were carried out.

The samples were made of second-grade pine and B15grade concrete had a span of $1 \mathrm{~m}$, as well as various 
types of connections connecting the upper (concrete) and lower (wooden) structural elements (Fig. 4). There was used a testing plant in the experimental research, the diagram and general view of which are shown in Fig. 5. The load on the samples was transferred through the metal distribution element 3 , the mass of which is taken into account in the total load. The load is transferred to the sample in thirds of the span, according to the design scheme (Fig. 5). To exclude the crumpling of the sample on the supports and in the places where the load is applied, metal gaskets 4 and 4.1 were used. The loading of the tested beam was carried out with a stepwise increasing load with a step of $50 \mathrm{kgf}(0.49 \mathrm{kN})$. The value of the deformations was determined after each load application step. Results. During the experiment, the samples were tested. The first of them is shown on the Fig.6.

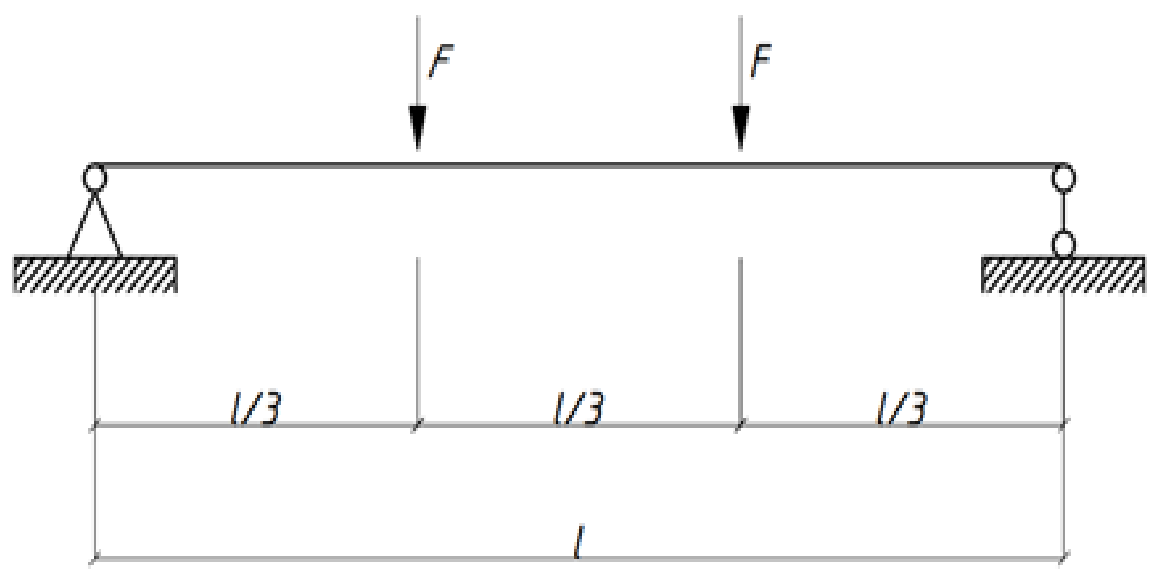

Figure 3: The design scheme for applying a load to a sample

a)
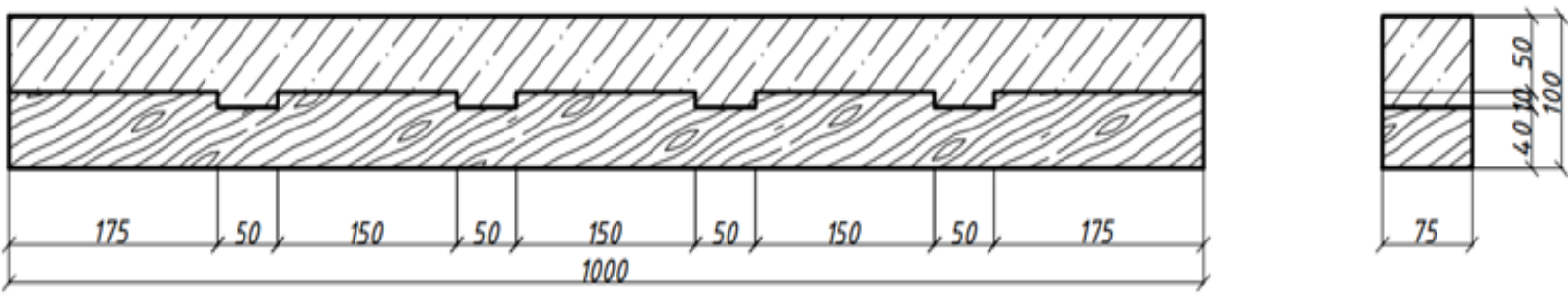

b)
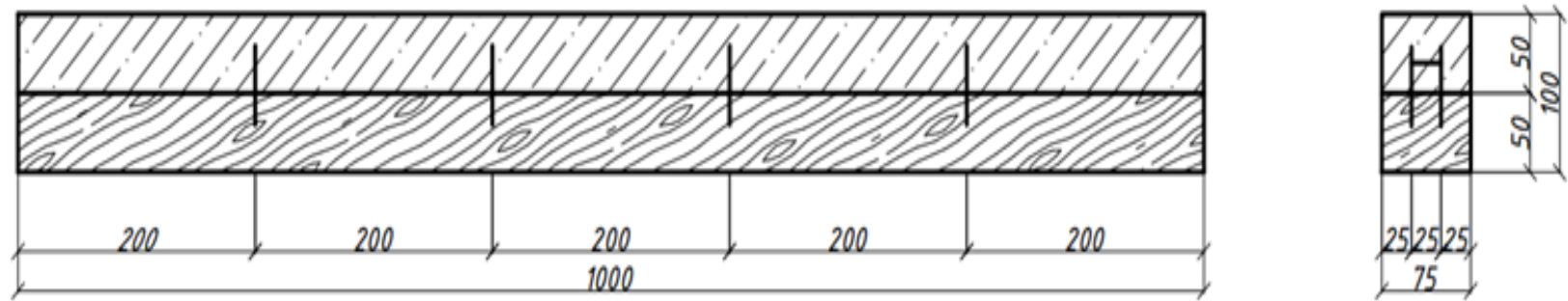

c)
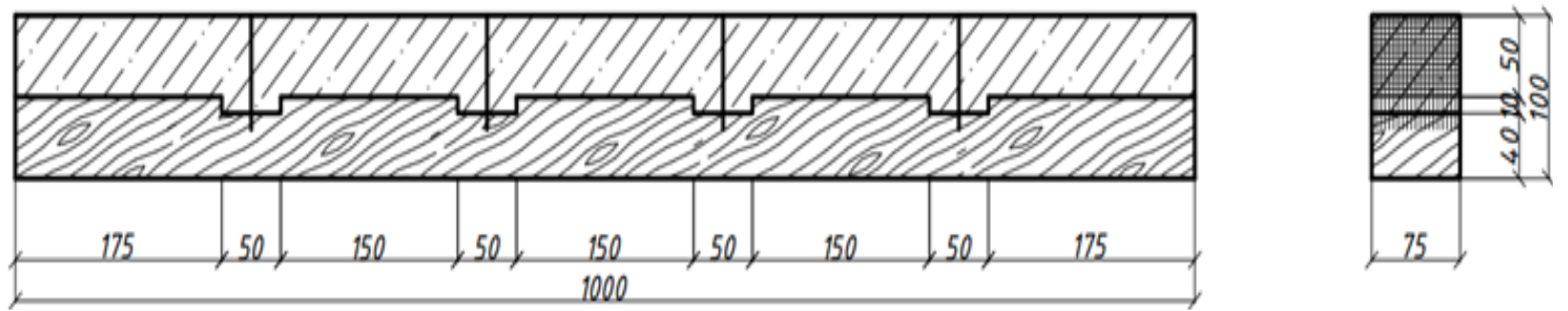

Figure 4: Schemes of the studied samples of wood-concrete beams: a - slots in a wooden element are used as fastening elements; $b$ - nails with a tie-wire act as fastening elements; $c$ - slots in a wooden element with additional reinforcement as fastening elements 


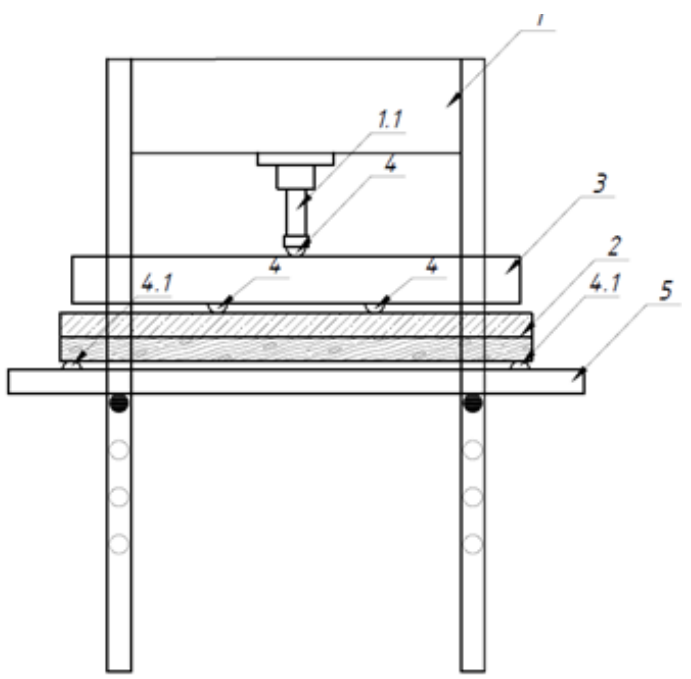

a)

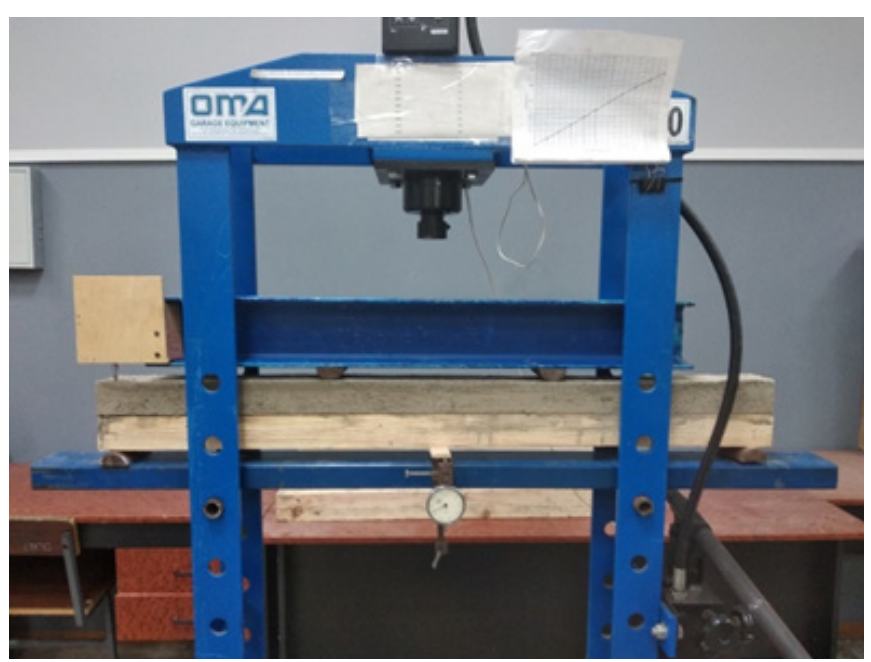

b)

Figure 5: Scheme (a) and general view (b) of the test plant: 1 - Press testing plant; 1.1 - Press; 2 - Sample; 3 - Distribution element; 4 - Transfer metal gaskets; 4.1 - Supporting metal gaskets

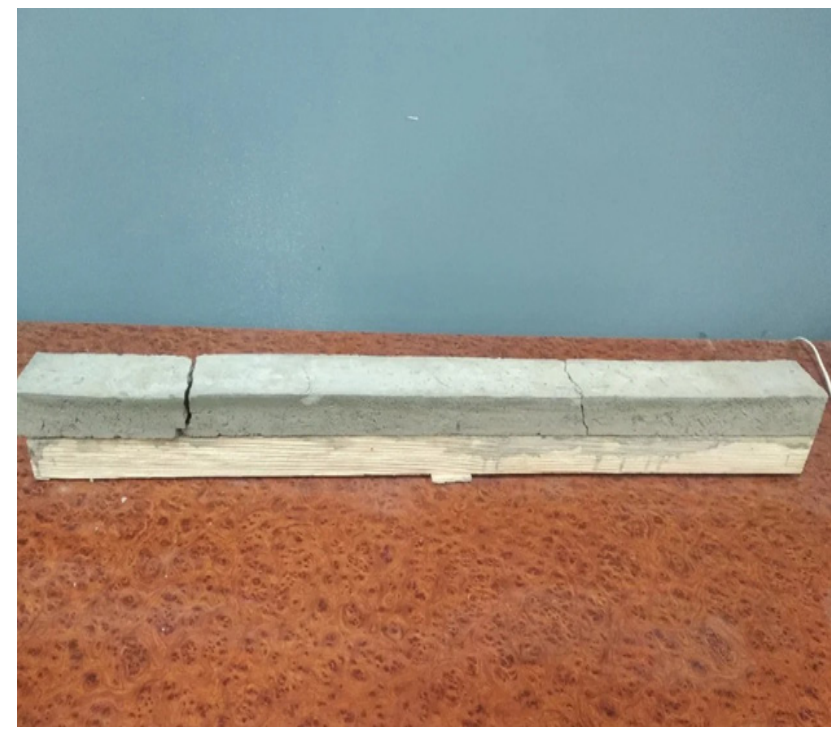

Figure 6: Tested sample of timber-concrete beam after the fracture.

\section{Deformations-load dependency graph (Deformations were measured in the middle of the span)}

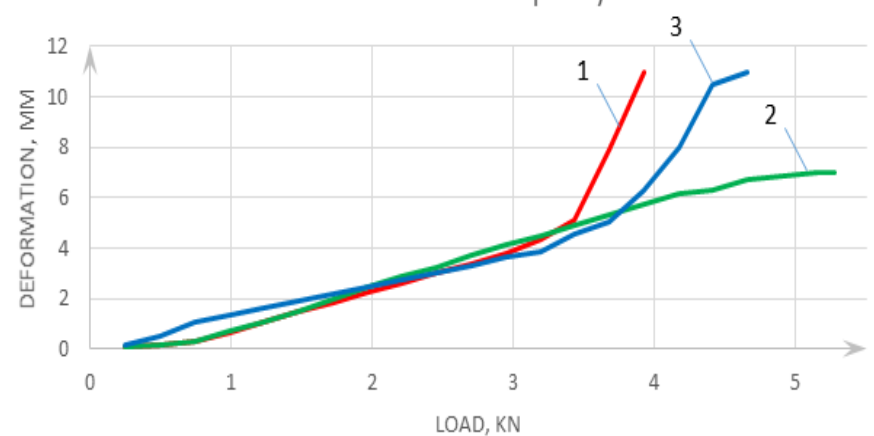

Figure 7: Deformations-load dependency graph. 1 - first sample; 2 - second sample; 3 - third sample.
It was found that the ultimate load for samples 1,2 , and 3 was $3.93 ; 5.26$ and $4.66 \mathrm{kN}$, respectively. The experimental research results are presented graphically in Fig. 6. The plotted dependence graph (Fig. 7) clearly shows that the first sample was deformed linearly up to a load of $3.44 \mathrm{kN}$, and the third sample was deformed linearly up to a load of $3.68 \mathrm{kN}$. It is noteworthy that the second sample was deformed linearly up to fracture, which occurred at $5.28 \mathrm{kN}$.

\section{DISCUSSION}

Linear deformation of the second sample may be explained by the type of connection used in it, which turned out to be the most effective in the operation of this wood-concrete beam, also allowing the structure to work longer according to the conceived scheme and withstand more load than other samples.

\section{CONCLUSION}

Based on a comparison of the theoretically obtained values and experimental data, we can see that the proposed calculation method allows, with the accuracy necessary in the context of the experiment, to determine the critical values of the force "F" and momentum "M" for the considered type of structure. It should be noted that during experimental studies, the observed destruction of the testing samples occurs at the more high-load levels compared to the theoretical data. This may occur because these studies were conducted under a short duration load, in contrast to the studies of European scientists. Also, it is worth taking into account that during the experiment there were created wood-concrete samples of various fastening methods, and using the obtained results can be helpful in further researches on this issue. 


\section{REFERENCES}

1. A Ceccotti (2002) Composite concrete-timber structures. Progress in Structural Engineering and Materials, 4:264-275, DOI: 10.1002/pse.126.

2. M.V. Lukin, E. Prusov, S. Roshchina, M. Karelina (2021) Multi-Span Composite Timber Beams with Rational Steel Reinforcements, Buildings 11(2):46, DOI:10.3390/buildings 11020046

3. A. Darby, T. Ibell, M. Evernden (2010) Innovative Use and Characterization of Polymers for Timber-Related Construction. Materials, 3, 1104-1124; doi:10.3390/ma3021104.

4. H. KIESLICH, K. HOLSCHEMACHER (2010) Composite Constructions of Timber and High-Performance Concrete. Advanced Materials Research Vols. 133-134 pp 1171-1176.

5. L. Zaccaro (2017) Timber-concrete hybrid innovations: A framework to evaluate economical and technical factors for the construction market. TRITA-BYMA, ISSN 0349-5752; 04.

6. E.C.Fischer, A.B.Shephard, A.Shinha, A.R.Barbosa (2020) Design of timber-concrete composite floors for fire, 11th International Conference on Structures in Fire (SiF2020), DOI:10.14264/44c4e56.

7. R. Vasiljevs, D. Serdjuks, J. Gerasimova, K. Buka-Vaivade (2019) Behaviour of Timber-Concrete Joints in Hybrid Members Subjected to Flexure, IOP Conference Series Materials Science and Engineering 660:012050, DOI:10.1088/1757899X/660/1/012050.

8. A. Dias, J. Skinner, K. Crews \& T. Tannert (2016) Timber-concrete-composites increasing the use of timber in construction, European Journal of Wood and Wood Products 74(3), DOI:10.1007/s00107015-0975-0.

9. M. Fragiacomo (2012) Experimental behaviour of a full-scale timber-concrete composite floor with mechanical connectors, Materials and Structures 45(11), DOI:10.1617/s11527-012-9869-3.
10. R.M.Gutkowski, J. Balogh, Lam. G. To (2010) Finite-Element Modeling of Short-Term Field Response of Composite Wood-Concrete Floors/Decks, Journal of Structural Engineering 136(6), DOI:10.1061/ (ASCE)ST.1943-541X.0000117.

11. J. Kanocz, V. Bajzecerova, S. Steller (2014) Timber Concrete composite elements with various composite connections Part 2: Grooved connection, WOOD RESEARCH 59 (4): 2014 627-638.

12. Monteiro, S.R.S., Dias, A.M.P.G. \& Negrão J.H.J.O. (2013). Assessment of Timber-Concrete Connections Made with Glued Notches: Test Set-up and Numerical Modeling. Experimental Techniques, 37(2).

13. J. Kanocz, V. Bajzecerova (2013) Timber - Concrete composite elements with various composite connections Part 1: Screwed connection, Wood Research 58(4):555-570

14. J. Kanocz, V. Bajzecerova (2015) Timber - Concrete composite elements with various composite connections Part 3: Adhesive connection, Wood Research 60(6):939-952.

15. M.A.Ali, V. Bajzecerova, V. Kvocak (2017) Design methods of timber-concrete composite ceiling structure, Magazine of Civil Engineering № 5 (73). P. 88-95, DOI:10.18720/MCE.73.8.

16. A. Yehia, Z. Ali (2018) Flexural behavior of FRP strengthened concrete-wood composite beams, Ain Shams Engineering Journal 9(4), DOI:10.1016/j. asej.2018.06.003.

17. S.G. Yemelyanov, E.G. Pakhomova, K.O. Dubrakova, S.V. Dubrakov (2019) Stability of statically indefinite physically nonlinear timber structural systems. Journal of Applied Engineering Science, DOI: 10.5937/jaes17-21686. 